\title{
Hamburger Prices and Spatial Econometrics
}

\author{
Arturs Kalnins \\ University of Southern California
}

This paper applies spatial econometrics to hamburger price data to assess the degree of substitutability of products and locations of spatially dispersed franchised chains. First, while intrachain price variation exists, I find that hamburger prices at neighboring outlets of different chains are spatially uncorrelated. I conclude that their products are not close substitutes, which provides an explanation for why price promotions have not raised market share. I do find spatial price correlation, however, among proximate outlets of separate franchisees within the same chain. This finding implies that customers view proximate locations of a chain as substitutes. *

\section{INTRODUCTION}

Economists, market researchers, and strategists have long recognized that products exhibit varying degrees of substitutability. Economists have found substitutability an important concept for determining boundaries of markets in antitrust analysis. For strategists and market researchers, the level of substitutability between (or among) products that appear similar is a vital piece of information for determining an appropriate pricing strategy for branded products within an oligopolistic industry.

In this paper, I use spatial econometric methods to assess the level of substitutability among products and locations of spatially dispersed multiple-outlet firms. I apply these methods to a crosssection of prices charged by 1385 locations of the four largest fastfood hamburger chains across Texas. If the prices at neighboring

\footnotetext{
*I would Like to thank Luc Anselin, Nick Argyres, Shantanu Dutta, Tom Gilligan, Francine Lafontaine, Julia Liebeskind, and Howard Marvel for reviewing previous drafts and making helpful comments. I would also like to thank seminar participants at the 2001 INFORMS College of Organization Science, the Academy of Management 2001 Annual Meetings, and the University of Southern California's Finance and Business Economics Department. Finally, I thank the two referees and the editor for their thorough and thoughtful comments.
} 
restaurants of different chains were spatially correlated, I would conclude that customers view their hamburgers as substitutes. In this case, lowering prices is likely to be effective for taking market share away from competition. Further, a relationship between prices of proximate restaurants within a chain would indicate that the units are sufficiently close together for consumers to view them as substitutes.

Reduced-form spatial econometric analysis of a cross section of prices is a valuable tool for assessing substitutability. The methods involved in this type of analysis differ from traditional methods used by economists to estimate cross-price elasticities of branded products (e.g., Gasmi et al., 1992) in that they do not require any knowledge of quantities sold. The major firms in the fast-food industry, for example, are very secretive about quantity information, making traditional cross-chain elasticity analysis infeasible in that industry. ${ }^{1}$ Rather, the spatial methods presented here are a spatial analogue to methods used by economists and strategists for analyzing temporal interfirm price variation without quantity data. Stigler and Sherwin (1985) and Slade (1986) used temporal price correlations of homogeneous products in different regions to assess whether the regions could be considered a part of the same market. More recently, Doane and Spulber (1994) and Paul et al. (2001) used temporal price correlations to document increasing market integration since deregulation of the natural-gas and retail gasoline industries. In their strategy text, Besanko et al. (1996) suggested that managers observe temporal cross-firm correlations of prices to assess product substitutability. I argue here that managers should also assess spatial cross-firm correlations of prices for the same reason.

To conduct this study, I surveyed 1385 restaurants of the largest four hamburger chains in Texas: Burger King, McDonald's, Wendy's, and Whataburger. ${ }^{2}$ Prices were obtained for the flagship hamburger at each chain - that is, the Whopper, Big Mac, Single, and Whataburger-as a la carte menu items and also for their associated "value meals." 3 hile price variation exists for the hamburgers and

$1 \mathrm{McDonald} \mathrm{s}$ will not even release aggregate sales information or quantities sold for an "average" outlet. Thomadsen (2002) uses the combination of consumer location and utility maximization as an alternative to the use of quantities in a structural model of spatial competition in the fast-food industry.

2 In 1999, 1857 restaurants of these four chains were listed in the Texas Sales and Use Tax Permit Holders database.

3 The Big Mac, the Whopper, and the Wendy's Single are the three most popular fast-food hamburger sandwiches among Americans, according to a survey by Bruskin Goldring Research of Edison, NJ. What I refer to as a "meal" includes french fries and a soda. 
their value meals, I find no correlation of prices across chains at the local restaurant level, and I interpret this finding as evidence that consumers do not view the hamburgers of the different fast-food chains as close substitutes. I do find, however, that price correlations exist across proximate outlets within each chain even when separate franchisees own the outlets. I interpret this finding to mean that the individual restaurants from a given chain are close enough to be competing against (or colluding with) each other.

The paper is organized as follows. Section 2 discusses the incentives of fast-food franchisors and franchisees and then presents anecdotal evidence regarding the importance, for both firm-level strategy and public policy, of a better understanding of cross-chain and intrachain competition. Section 2 also presents summary data about prices and price variation among fast-food chains. Following the presentation of the price data, Section 3 presents details of the spatial econometric method. Section 4 discusses the data and definitions of variables, and Section 5 contains a discussion of the empirical results. Concluding remarks are found in Section 6 .

\section{Competitive Considerations And InCENTIVES WITHIN FAST-FOOD CHAINS}

\subsection{INCENTIVES OF FRANCHISORS AND FRANCHISEES}

In a typical franchise agreement, a franchisee pays an up-front fee along with an annual sales royalty to the franchisor (e.g., the McDonald's Corporation) in exchange for the use of a trademark and associated knowledge at a specified geographic location (often a single outlet such as a restaurant). The franchisee keeps the residual profit after paying the royalty and expenses associated with the maintenance of the outlet. These residual profits are usually substantial in large chains, almost one hundred thousand dollars for an average restaurant in the case of McDonald's in 1989, even after the owner is compensated for management and for capital invested in the outlet (Kaufmann and Lafontaine, 1994). Existing franchisees often are given the rights to open additional outlets if their adherence to the chain's standards is deemed satisfactory. This practice by the four chains in this study has resulted in a landscape populated by both single-outlet owners and multiple-outlet owners of various sizes. Among the 1385 restaurants for which I have valid price data, single- 
outlet owners owned only 82 .

The fact that the franchisor receives a royalty on sales rather than profits creates tension between the franchisors and franchisees regarding price promotions as well as issues of restaurant location. If the franchise relationship were a single-period game between the two parties, the franchisor would clearly rather maximize sales than franchisee profits. However, the franchisor may face serious legal sanctions and public-relations problems if it consistently acts in opposition to the interests of the franchisees. These issues are explored in more detail in the context of price promotions and encroachment in the following sections.

\subsection{Cross-Chain COMpetition}

In the 1990s, the nationally active chains such as Burger King and McDonald's attempted to compete on many dimensions, including new-product introductions and tie-in promotions with films and television programs. Pricing promotions, however, remained central as their default strategies. The stated rationale for the promotions has typically been (1) to gain market share at the expense of other chains, and (2) to attract new customers unfamiliar with the chain's products (see, e.g., Pledger, 1997; McDowell and Ross, 1997). Interestingly, while the fast-food chains have acknowledged that a large portion of their revenues come from steady customers known as "heavy users," selling larger quantities to these regular customers has not become the focus of the firms' marketing efforts (Ordonez, 2000).

McDonald's, for example, made national headlines with its "Campaign 55," in which customers were offered a Big Mac for 55 cents. McDonald's official position on Campaign 55 was that it would be very effective in increasing market share at the expense of competitors like Burger King and Wendy's and in attracting new customers. Independent experts disagreed on both points (see, e.g., interviews with industry analysts in Pledger, 1997). Further, many franchisees criticized the idea. One disgruntled McDonald's franchisee said of the campaign, "All I know is that we've been down for five or six quarters and our competitors are doing well and I don't see them selling 55cent hamburgers." ${ }^{4}$ In the end, the campaign did not raise market share. 
The difference in stated opinions on the potential of Campaign 55 between the McDonald's Corporation and the franchisees may be the result of their different incentives rather than the results of different analyses or beliefs. The fact that a sales promotion can result in the franchisor's sales royalty increasing while the franchisee's profits decrease may be the unstated reason for the franchisors' typically greater enthusiasm for such promotions. Further, the fact that franchisors need to instigate price promotions implies that they and franchisees are at odds on this issue to some extent; franchisees who are profit maximizers would choose lower prices of their own accord if they perceived that the quantity demanded at current prices was too low. Yet, similar disagreements exist even among the franchisors' corporate officers who do not have any obvious incentive differences. Burger King CEO Jim McLamore described a serious disagreement with the company's chief marketing officer about whether lowering prices was necessary to retain customers in light of a McDonald's discounting strategy. McLamore was in favor of lowering prices, while the marketing officer was against such a move (McLamore, 1998, p. 235).

The fundamental question underlying these stated opinions on the effectiveness of price promotions for gaining or defending market share from competitors relates to the degree of substitutability of the products in the eyes of most consumers. On the one hand, if the chains each have a loyal group of customers, then lower prices are unlikely to increase market share at the expense of a competitor. Rather, lowering prices amounts to the chain selling the products cheaper to inframarginal customers within its loyal group. In this case, the price reduction would only make sense if the additional quantities sold to existing customers were large enough to make up for the reduced revenue on inframarginal sales. On the other hand, if the customers view the products of the different chains as substitutes, then lowering prices would be an effective way of capturing market share from competitors.

\subsection{INTRACHAIN COMPETITION AND ENCROACHMENT}

In addition to possible price competition from other chains, the individual franchisees may face competition from restaurants owned by others within the same chain. In this case, because the menu items are identical, the substitutability in question is strictly that of location. If locations are close enough to be viewed as 
substitutes by consumers, intrachain competition or collusion will result. As the individual franchisees are the residual claimants, intrachain competition is obviously detrimental from their point of view, while benefiting the franchisor and the consumer. Many franchisees have loudly complained of "encroachment"- that is, the opening of new restaurants of the same chain within the vicinity of a franchisee's existing restaurant - because it reduces their sales. ${ }^{5}$ Franchisees of the chains covered in this study have no territorial exclusivity built into their contracts and are thus susceptible to such encroachment. Despite this, some courts have ruled that the franchisor can be held liable if the franchisee loses sales as a result of the establishment of a new outlet of the same chain nearby. ${ }^{6}$ Franchisees have also appealed to the Federal Trade Commission to force franchisors to admit the possibility of encroachment in the Uniform Offering Circulars that franchisors are required to show all prospective franchisees. ${ }^{7}$ Further, a bill was recently introduced in the U.S. Congress that would give the closest franchisee a right of first refusal for the ownership of any new outlets that might impinge on the sales of his or her existing outlets. ${ }^{8}$

Despite the publicity that encroachment has received, existing evidence comes only from anecdotal accounts of individual franchisees. It is not clear whether intrachain competition is widespread or exceptional. Analyses of spatial intrachain price correlation across outlets of different owners, such as that presented in this paper, can provide more systematic evidence regarding the existence of intrachain competition.

\subsection{Observed Price Variation and Franchisee incentives}

To make inferences about product and location substitutability based on observed prices at different locations, it

5 The topic of encroachment has probably received more attention in the trade press over the last several years than any other issue related to franchising. See Blair and Lafontaine (2002) for an extensive discussion of this issue.

6 In Burger King v. Scheck, the court ruled that the plaintiff was "entitled to expect that Burger King will not act to destroy the right of the franchisee to enjoy the fruits of the contract." This ruling was overturned in 1996.

7 See the Federal Register, October 22, 1999. It reads: "These commenters [franchisees] contend that encroachment has a devastating effect upon an individual franchisee who does not have a contractual right to an exclusive territory, and they urge the Commission to ban encroachment as an abusive and unfair practice."

8 HR 3308, the Small Business Franchise Act, introduced by Howard Coble (R-NC) and John Conyers (D-MI). 
must be true that prices at the individual restaurants of the chains are set independently by franchisees to maximize residual profits at their location. As mentioned earlier, a majority of restaurants of the four chains in this study are owned by franchisees independent of the franchisor. In 1999, franchisees owned all 393 Burger King restaurants in operation in Texas, McDonald's franchisees owned 715 of 780, Wendy's franchisees owned 189 of 268, and Whataburger franchisees owned 139 of 416.

Franchisees have an incentive to set prices at levels that maximize their residual profits. Further, I argue that franchisees have the information required to make profit-maximizing price changes and that they do not face prohibitive menu costs (the costs of printing new menus) that would be a barrier to price changes. While corporate executives of the franchisor may not know how substitutable their products are for those of competitors on a national scale, I assume that the franchisees do know, at least in the vicinity of their outlets. They can easily check the prices at neighboring restaurants and assess the effects of any price changes on their own sales. Also, fast-food franchisees have a very limited menu of 30 to 40 individual prices to manage. As a result, costs involved with price changing should not pose a barrier to competitive price responses, as they do, for example, for supermarkets that have tens of thousands of prices to manage (Levy et al., 1997). Finally, they typically only have to change prices on one or two price boards. Thus, they are unlikely to incur the menu costs faced by other restaurants that have to print new menus when changing prices.

Nonetheless, franchisors may pressure franchisees to standardize everyday prices, much as they do with national price promotions. In May 1999, the time of the survey, the ability of franchisees to set prices totally independently of the franchisor was not clear. Until November 1997, it was per se illegal for the franchisor to dictate prices in franchised outlets. However, as a result of the Supreme Court decision in Khan vs. State Oil, the legality of maximum resale price maintenance is now decided on a case-by-case basis. Minimum resale price maintenance, however, remains per se illegal. As of July 2000, McDonald's states that franchisees determine their own prices but that they take into account "recommended prices." 9

Yet, the prices found in the May 1999 survey exhibited 
variation that appears consistent with independent price setting among franchisees, as do those found in other studies (e.g., Lafontaine, 1999; Thomadsen, 2002). If the franchisors are in fact setting maximum prices, these do not appear to be binding constraints for most franchisees. Further, franchisors would be unlikely to set different maximum prices for different franchisees, because such action would generate considerable animosity among franchisees.

Table I shows the average prices of the 1385 outlets that we were able to contact, out of a total of 1870 outlets of the four chains in Texas that were listed in two sets of online yellow pages. Prices shown are without tax and without cheese for the four flagship hamburgers as a la carte items and for their associated value meals. These prices were also the regular prices and not temporary specials or promotional prices. Further, the composition and size of items in the value meals were entirely consistent within each chain. More information about the survey can be found in Section 5 and in the Appendix.

TABLE I.

\begin{tabular}{|c|c|c|c|c|c|c|c|c|}
\hline \multirow[b]{2}{*}{ Chain } & \multirow[b]{2}{*}{ Commodity } & \multicolumn{5}{|c|}{ Price } & \multicolumn{2}{|c|}{ No. of Outlets } \\
\hline & & Mean & $\begin{array}{l}\text { Std. } \\
\text { Dev. }\end{array}$ & Min & $\operatorname{Max}$ & Mode & Total & $\begin{array}{l}\text { Within } 5 e \\
\text { of Mode }\end{array}$ \\
\hline \multirow[t]{2}{*}{ Burger King } & Whopper & $\$ 1.54$ & $\$ 0.41$ & $\$ 0.99$ & $\$ 2.49$ & $\$ 0.99$ & \multirow[t]{2}{*}{259} & 70 \\
\hline & Whopper meal & $\$ 3.26$ & $\$ 0.23$ & $\$ 1.99$ & $\$ 3.65$ & $\$ 3.29$ & & 82 \\
\hline \multirow{2}{*}{ McDonald's } & Big Mac & $\$ 2.01$ & $\$ 0.10$ & $\$ 1.85$ & $\$ 2.99$ & $\$ 1.99$ & \multirow[t]{2}{*}{589} & 353 \\
\hline & Big Mac meal & $\$ 3.26$ & $\$ 0.17$ & $\$ 2.97$ & $\$ 3.99$ & $\$ 3.29$ & & 230 \\
\hline \multirow[t]{2}{*}{ Wendy's } & Single & $\$ 1.90$ & $\$ 0.13$ & $\$ 1.59$ & $\$ 2.89$ & $\$ 1.89$ & \multirow[t]{2}{*}{207} & 136 \\
\hline & Single meal & $\$ 3.23$ & $\$ 0.13$ & $\$ 2.95$ & $\$ 4.19$ & $\$ 3.19$ & & 133 \\
\hline \multirow[t]{2}{*}{ Whataburger } & Whataburger & $\$ 1.99$ & $\$ 0.09$ & $\$ 0.99$ & $\$ 2.15$ & $\$ 1.99$ & \multirow[t]{2}{*}{330} & 290 \\
\hline & Whatabg. meal & $\$ 3.87$ & $\$ 0.12$ & $\$ 3.69$ & $\$ 4.89$ & $\$ 3.79$ & & 162 \\
\hline
\end{tabular}

\section{THE REDUCED-FORM MODEL OF SPATIAL PRICE COMPETITION}

\subsection{The Spatial Econometric Model}

In this section, I present a model of spatial price competition that will help to establish whether each fast-food chain caters to a distinct and loyal group of consumers or whether consumers view their products as substitutes. This model is also applied to location 
substitutability in the case of proximate neighbors of the same chain. The underlying reasoning is straightforward. If, on the one hand, the flagship burgers of the different chains are viewed as good substitutes, franchisees will maximize profits by setting prices based partly on the prices of their proximate competitors. In this case, we should observe each price to be partially determined by neighbors' prices. On the other hand, if customers do not view the products of two restaurants as substitutes, the presence of a low or high price at a particular restaurant will not motivate the franchisees of neighboring restaurants to lower or raise their prices.

The purpose of spatial econometrics is to determine whether any spatial relationship of the variables is merely random or responds to a pattern of spatial dependence. Spatial econometrics has been used extensively to measure sociological and technological diffusion processes (e.g., Anselin et al., 1997; Tolnay, 1995) and in development economics (Case, 1991). Spatial techniques have also been used to test for clustering of contract types among gasoline retailers (Pinkse and Slade, 1998). Recently, Pinkse et al. (2002) used spatial techniques to show that price competition among gasoline wholesalers is highly localized. An extensive theoretical discussion can be found in Anselin (1988).

Two types of spatial correlation can be modeled within regression models. The first case, represented by the first line of equation (1) below, is a causal relationship of the dependent variables of other observations on each focal observation. This model is analogous to the temporal autoregressive model that is used, for example, to test habit- persistence theory. Because the full vector of left-hand-side variables also appears on the right-hand side, this model would be particularly similar to a hypothetical temporal autoregressive model where the present is influenced by both the past and the future. The second case, represented by the second line of equation (1), represents a correlation of the error terms of other observations on each focal observation and is analogous to an autoregressive error model used in temporal time series. The most general model, containing both types of spatial correlation, can be written: 


$$
\begin{aligned}
& y=\sum_{a} \rho_{a} W_{a} y+X \beta+\varepsilon, \\
& \varepsilon=\sum_{b} \lambda_{b} M_{b} \varepsilon+\xi,
\end{aligned}
$$

where

$$
\begin{aligned}
y= & \text { a vector of } n \text { observations of the dependent variable (in this } \\
& \text { case, the price), } \\
\rho_{a}= & \text { the estimated autoregressive coefficients associated with matri- } \\
& \text { ces } W_{a \prime} \\
W_{a}= & \text { the } n \times n \text { spatial weight matrices, where } a=1, \ldots, A \text {, the } \\
& \text { total number of matrices, } \\
X= & \text { the } n \times k \text { matrix of exogenous variables, } \\
\beta= & \text { the vector of the } k \text { parameters to be estimated, } \\
\varepsilon= & \text { the vector of } n \text { error terms, with } E[\varepsilon \mid X]=0, \\
\lambda_{b}= & \text { the estimated autoregressive coefficients associated with matri- } \\
& \text { ces } M_{b v} \\
M_{b}= & n \times n \text { spatial weights matrices where } b=1, \ldots, B, \text { the total } \\
& \text { number of matrices, } \\
\xi= & \text { the vector of } n \text { spherical-error terms. }
\end{aligned}
$$

\subsection{Specification of the Weight Matrices}

The $n X n$ spatial weight matrices $W$ and $M$ consist of exogenously specified elements $W j$ and $m_{t} j$ that capture the neighbor relations of observations $i$ and $j$-that is, the extent to which their prices should be correlated causally or via the error terms. In the case of price competition among outlets of franchised chain firms, two such matrices that can appear either as $W$ or $M$ are of particular interest. The first of these matrices consists of the neighbor relations of an outlet with others owned by different owners within the same chain, while the second consists of an outlet's relations with outlets of other chains. Owners often own multiple outlets within each chain, and these outlets are often neighbors (Kalnins and Lafontaine, 2002). Obviously, such outlets do not compete. Thus, within the same chain matrix, other outlets of the same owner as the focal outlet are not considered neighbors. This is not an issue for the matrix of neighboring outlets of other chains, as no owners of outlets across multiple chains exist within this sample.

These two matrices are referred to below as $W_{s}$ and $W_{c}$ in the case in which they specify the spatial lag of the dependent variable, and as $M_{s}$ and $M_{c}$ in the case in which they specify the spatial lag of 
the error term. The subscript $s$ always refers to the same-chain, otherowner neighbor matrices, and the subscript $c$ to the cross-chain neighbor matrices.

I use two approaches to define the value of each element $w_{i j}$ and $m_{i} j$ within the $W$ and $M$ matrices: a distance-based approach and a contiguity-based approach. Simply put, the distance-based approach assumes a mileage threshold within which all restaurants $j$ are competitors of focal observation $i$ and outside of which they are not. Even in rural settings, where travel is relatively fast, fast-food customers will rarely travel over three miles for their meals, and almost never over five (Salvaneschi, 1996). Therefore, a distance cutoff of four miles was chosen for the results presented in this paper. One drawback of this approach is that the mileage threshold remains fixed regardless of population density in the area.

A second approach of defining neighbor relations is based on Hotelling models of spatial competition. The level of competition between two outlets is driven by whether the outlets are contiguous - that is, whether they share a market boundary. A Hotelling-style model presented by Levy and Reitzes (1992), for example, showed that both for cases of spatial competition and for cases of merger of (or collusion among) neighboring outlets, the reaction functions for price include only those outlets that share a market boundary. One major advantage of the use of contiguity to assess neighbor relations is that the boundaries naturally take into account heterogeneity in population density in a way that the distance threshold does not. In rural areas, the restaurants that share a boundary will likely be farther apart than in

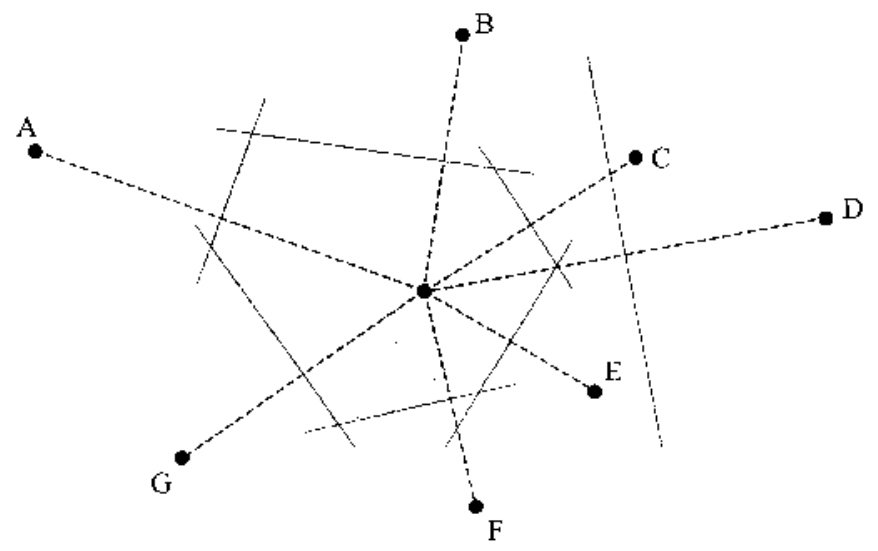

FIGURE 1. A THIESSEN POLYGON 
urban areas. Yet, they will remain neighbors, regardless of the distance between them.

In a two-dimensional plane, market boundaries are formally specified using Thiessen polygons (see, e.g., Kalnins and Lafontaine, 2002). A Thiessen polygon surrounding a given outlet is constructed by drawing lines between that outlet and all other outlets either from that same chain or from competing chains, depending upon which matrix is being constructed. These lines are then perpendicularly bisected in their middle. In any direction from outlet $i$, the bisecting line that is closest to outlet $i$ forms a side of outlet is polygon in that direction and represents a market boundary around outlet i. Figure 1 illustrates this process. In this figure, outlets $A, B, C, E, F$, and $G$ all are contiguous with the middle outlet, but outlet $D$ is not. Yet, outlets $A$ and $D$ are at the same distance from the middle outlet. Therefore, the distance-based approach would treat both $A$ and $D$ as competitors of the focal outlet as long they fall within a certain threshold, while the contiguity-based models would only consider $A$ to be a competitor.

Once the neighbors of an outlet have been determined, the elements of the matrices need to be weighted. To generate the results presented below, I use $W$ and $M$ matrices that, for the distance-based definition of neighbor relations, weight all neighbors by their inverse distance to the focal observation $i$ and assign nonneighboring outlets a value of zero. For the contiguity-based definition of neighbor relations, Boots (1980) and other geographers have suggested weights proportional to the angle of exposure around the Thiessen polygon. Considering Figure 1 again, the angles of exposure for outlets $B$ and $G$ are substantially larger than those for outlets $C$ and $F$ and would indicate more intense competition with the focal outlet. All matrices are then row-standardized by dividing each element of a row by the value necessary for the sum of all elements in that row to equal one. Row-standardizing allows the coefficients $p$ and $A$ to be easily interpreted as an effect of the value of the dependent variable at the neighboring outlets-not an effect of the number of neighboring outlets, as it would be if the neighboring elements were all set equal to their raw inverse distances, for example. 


\subsection{ESTIMATION TECHNIQUES}

Estimation of the general model in equation (1) is difficult, yet the consequences of ignoring spatial dependence in models can be substantial. On the one hand, if a causal relationship of the dependent variables of nearby observations does exist, but the model is estimated without the spatial autoregressive term, then a significant explanatory variable has been omitted, and the estimated coefficient vector $f 3$ will be biased. On the other hand, if the autoregressive term is included in an OLS regression, the value of $p$ is biased as well as asymptotically inconsistent.

Unfortunately, maximum likelihood is not practical for the general model; while first-order conditions can be written out simply enough (see Anselin, 1988, pp. 61-63), these equations contain determinants of matrices that can be found by the rules of linear algebra only for certain special cases of the model. For example, in a case with only one matrix $W$ and no $M$ matrices, often referred to as the spatial lag model, the solution of the first-order conditions of the likelihood function can be reduced to a concentrated likelihood function that is nonlinear in only one parameter. In this case, the log likelihood function can be written as

$$
\begin{aligned}
L=-\frac{n}{2} \ln \left(2 \pi \sigma^{2}\right)+\ln \mid I & -\rho W \mid \\
& -\frac{1}{2 \pi \sigma^{2}}(y-\rho W y-X \beta)^{T}(y-\rho W y-X \beta) .
\end{aligned}
$$

Further, the maximization of the equation can be greatly simplified, as the determinant in the above equation can be written as a function of eigenvalues. Specifically,

$$
|I-\rho W|=\prod_{i}\left(1-\rho \omega_{t}\right),
$$

where $w_{i}$ is the $i$ th eigenvalue of $W$ (Ord, 1975). Because of this equality, equation (2) can be rewritten as a concentrated likelihood function with the only unknown being the autoregressive parameter $p$ (Anselin, 1995). The value of $p$ maximizing the concentrated likelihood function is then found by evaluating possibilities within the range between the smallest and largest eigenvalues of the matrix $I-p W$ using a bisection procedure.

Unfortunately, the relationship of the determinant and eigenvalues no longer holds when there is more than one $W$ matrix, 
even without any $M$ matrices in the equation (Hepple, 1976;

Brandsma and Ketellapper, 1979). Thus, the case under consideration, with separate matrices for same-chain competitors and other-chain competitors included simultaneously, cannot be easily solved using maximum likelihood. ${ }^{10}$

While ML does not allow multiple $W$ matrices or a combination of $W$ and $M$ matrices, information about the possible effect of the spatial error of a distinct matrix $M$ can be gained by applying a Lagrange multiplier test to the residuals of an ML estimate of a model that includes a single $W$ matrix. For my purpose, the specification is to estimate $p_{s}$ for $W_{s}$, the matrix of neighbor outlets of different owners within the same chain. The residuals can then be used for a test of whether the coefficient $X_{c}$ of $M_{c}$, the matrix of neighboring outlets of other chains, is significant.

The Lagrange multiplier statistic takes the form

$$
\mathrm{LM}=\frac{\left(e^{\prime} M_{c} e / \sigma^{2}\right)^{2}}{\operatorname{tr}\left(M_{c}^{2}+M_{c}^{\prime} M_{c}\right)-\operatorname{tr}\left(M_{c} W_{s}+M_{c}^{\prime} W_{\mathrm{s}}\right) A^{-1} \operatorname{var}\left(\rho_{\mathrm{s}}\right)},
$$

where $e$ is the residual from the ML estimation of the spatial lag model, $A=I-p W, \operatorname{var}\left(\mathrm{p}_{s}\right)$ is the estimated asymptotic variance of the lag coefficient, and $t r$ is the trace operator. Under the null hypothesis of $X_{c}=0$, equation (3) will have a chi-squared distribution with one degree of freedom. Anselin (1988,105-106) explained the derivation of this statistic.

The Lagrange-multiplier statistic tests the appropriateness of a model with a $W$ matrix, containing neighbor relations for outlets within each chain, and an $M$ matrix, containing the neighbor relations for outlets of other chains. This specification is theoretically appropriate if there is no cross-chain price competition, but instead the demand and supply conditions at nearby outlets of the different chains are spatially correlated. Such correlation may affect prices even if most customers do not view the products as substitutes at all. Even if, for example, half of highly paid downtown office workers strongly prefer Burger King and half prefer McDonald's, both groups still would be willing to pay more at their respective favorite downtown 
restaurants than would workers or residents of less affluent areas. Thus, prices at McDonald's and Burger King would be spatially correlated in the downtown area even without any actual competition or collusion. Similarly, differences in costs may be spatially correlated. As potential employees are likely to view jobs in proximate restaurants as substitutes, even if customers do not view the products as such, unobserved labor-supply variation could lead to spatially correlated prices across chains.

In light of the difficulty of estimating models with multiple $W$ matrices (even in cases without $M$ matrices), Anselin (1988, pp. 82-85) suggested the use of a standard instrumental-variables approach. Such a model can then be estimated using the well-known two-stage least- squares method. For each $W$ matrix, a set of instruments is specified that are correlated with $W y$ but not with We. Anselin suggested using $W X$, the lagged values of the exogenous variables. While this specification has merit in general, an efficient use of this approach requires that the exogenous variables have a highly significant effect on the dependent variable.

To increase efficiency beyond that possible via lagged exogenous variables, I take advantage of an interesting attribute of the spatial competition of fast-food outlets, which is that many franchisees own multiple outlets. These owners price similarly across their outlets, so for both hamburger prices and meal prices ANOVA analyses decisively reject a null hypothesis that within-owner price variation is equal to that between owners. The within-owner price variation is far lower. As a result, the prices at an owner's outlets that are not neighbors of a focal outlet can be used as instruments for those that are. Of course, some franchisees own only one outlet (or only outlets that are all neighbors to a focal outlet), and those few outlets that are surrounded by such outlets must be assigned instruments based only on the spatially lagged exogenous variables. ${ }^{11}$ 


\section{DATA AND VARIABLES}

\subsection{Data Collection and Preparation}

The data used in this study come from three sources: the Texas Sales and Use Tax Permit Holder Information database, a phone survey based on online yellow pages, and the 1990 US Population Census. The Texas Sales and Use Tax database contains complete street-address and ownership information for all sales-tax-paying organizations in Texas, including 1857 individual fast-food restaurants of the four chains in this study. To obtain phone numbers for these restaurants, I used two sets of online yellow pages: Mapsonus.com and Yahoo.com. The combination of these two sets of yellow pages yielded 1870 phone numbers purportedly of restaurants of the four chains. Finally, all the demographic control variables were obtained at the zip-code level from the 1990 US Population Census.

To collect pricing information, research assistants attempted to contact all of the 1870 phone numbers found in the yellow pages. Up to three calls were placed to each restaurant at different times of the day. Price information was successfully collected for 1385 restaurants. The callers asked for the price without tax and without cheese of the four a la carte hamburgers and of their associated value meals. They also verified that these prices were regular prices and not temporary specials or promotional prices. Finally, they confirmed that the composition and size of items in the meals were entirely consistent within each chain. For detailed information about the survey, see Appendix A.

The locations of all 1857 restaurants for which I have valid address information from the Sales Tax Permit Holder file were then geocoded - that is, they were assigned longitude and latitude (longlat) coordinates based on their street addresses. The geocoding process available from a leading online vendor (Etak.com) assigns coordinates based on three methods, each with a different level of accuracy. First, the actual street number can be identified in the database of longlat points. The accuracy of this method is usually within 250 feet. Second, even if no longlat points exist for the particular street, the street address can be identified as belonging to a particular group of nine-digit zip codes, yielding a centroid fairly close to the actual location. This method is typically accurate to within a quarter mile. Third, the centroid of the five-digit zip code is used as a proxy for the location. Of the total of 1385 restaurants with price information used as observations, 1121 , or $81 \%$, could be identified 
based on the street number. Another 163 , or $12 \%$, could be

TABLE II.

\begin{tabular}{|c|c|c|c|c|}
\hline Statistic & Mean & Std. Dev. & Min & Max \\
\hline Price of a la carte hamburger & 0.00 & 0.20 & -1.00 & 0.99 \\
\hline Price of value meal & 0.00 & 0.17 & -1.27 & 1.01 \\
\hline Log same-chain density & 1.16 & 0.80 & 0.00 & 2.94 \\
\hline Log other-chain density & 2.05 & 0.85 & 0.00 & 3.56 \\
\hline Restaurants (100s) & 0.81 & 0.47 & 0.00 & 2.28 \\
\hline Population $(100,000 \mathrm{~s})$ & 0.26 & 0.14 & 0.00 & 0.80 \\
\hline Per cap. income $(\$ 100,000 \mathrm{~s})$ & 0.14 & 0.06 & 0.00 & 0.49 \\
\hline Gas stations (10s) & 0.76 & 0.45 & 0.00 & 2.10 \\
\hline Total retail outlets (1000s) & 0.35 & 0.19 & 0.01 & 0.94 \\
\hline Hotel rooms $(10,000 \mathrm{~s})$ & 0.05 & 0.07 & 0.00 & 0.67 \\
\hline Company-owned restaurant & 0.23 & 0.42 & 0.00 & 1.00 \\
\hline Log age of restaurant & 1.93 & 0.77 & 0.00 & 3.40 \\
\hline Log owner's years as franchisee & 2.54 & 0.80 & 0.00 & 3.43 \\
\hline Log number of outlets owned & 2.83 & 1.60 & 0.00 & 5.62 \\
\hline
\end{tabular}

Prices measured as difference from mean price of each chain for that item.

identified via the nine-digit zip code, leaving 101, or $7 \%$, that relied on the inaccurate five-digit zip code.

\subsection{Measurement of Variables}

This subsection discusses the measurement of all variables other than the weight matrices. Descriptive statistics for all variables are presented in Table II.

First, for the dependent price variables, I subtract the mean of each chain's price for that item from each price. As shown in Table I, each chain has a different mean price for each item. So, what I test in the case of cross-chain competition is whether prices that are above (below) average at one location of one chain have an influence on whether prices at the neighboring locations of other chains are above (below) average.

I construct measures of density of other outlets surrounding each focal outlet using the locations of all 1857 restaurants in the Sales Tax Permit Holder database, not just the ones for which I have valid pricing information. The same-chain and cross-chain density variables are measured by the count of outlets within an arbitrary fixed radius from the focal outlet. The results presented below use a four-mile radius. The population and income variables come from the 1990 Population Census zip-code data. This data provided these variables for all but thirteen zip codes with restaurants in this sample. For the thirteen zips, I used the populations and income of the closest 
zip code for which the census data contained valid information. The restaurant, retail-outlet, and gas-station count variables for 1999, also aggregated at the zip-code level, are taken from the Sales Tax Permit Holder file, which is also the source for the primary data analyzed here. The hotel-room count data for 1999 are taken from the Texas Hotel Tax Permit Holder file.

Further, company-owned (franchisor-owned) restaurants may have incentives to charge lower prices than franchisee-owned outlets. Lafontaine (1998) discussed in detail the many reasons for the different incentives. For example, the franchisors receive the residual profit from the company-owned outlets, while they make a percentage of sales as a royalty from each franchisee-owned outlet. As the franchisor does not face the additional cost of a sales royalty, their monopoly equilibrium price at a company-owned outlet will be lower than that at a franchisee-owned outlet. A second example is that because the franchisors receive the sales royalties from the franchisees, they benefit when the franchisees increase sales. Low prices at company-owned outlets may generate a positive demand externality-that is, they may attract new customers, who will then frequent other outlets of the same chain.

\section{RESULTS AND DISCUSSION}

\subsection{RESULTS}

The first set of four columns of Table III presents estimation results for the a la carte hamburger, and the second set of four columns presents results for the value meals. The first two columns within each set of four incorporate spatial dependence via $W$ matrices defined by the four-mile distance radius, while the last two columns use $W$ matrices in which neighbors are defined using contiguity. The odd-numbered columns use ML estimation; as discussed earlier, ML can only accommodate a single $W$ matrix. I therefore run the estimation with only the matrix $W_{s}$, which includes the neighbors of the same chain but belonging to other owners. To assess whether the matrix of other chain neighbors plays a role, I conduct the Lagrangemultiplier test on the residual errors from all of the ML estimations. The results of those tests are presented at the bottom of the tables, just above the $\mathrm{R}^{2}$ statistics. The even-numbered columns present results with an instrumental variable in place of the lagged dependent variable. 
For both the hamburger and its associated value meal, the prices at neighboring same-chain outlets belonging to different owners have an effect on the price at the focal outlet. The parameter $p_{s}$ associate

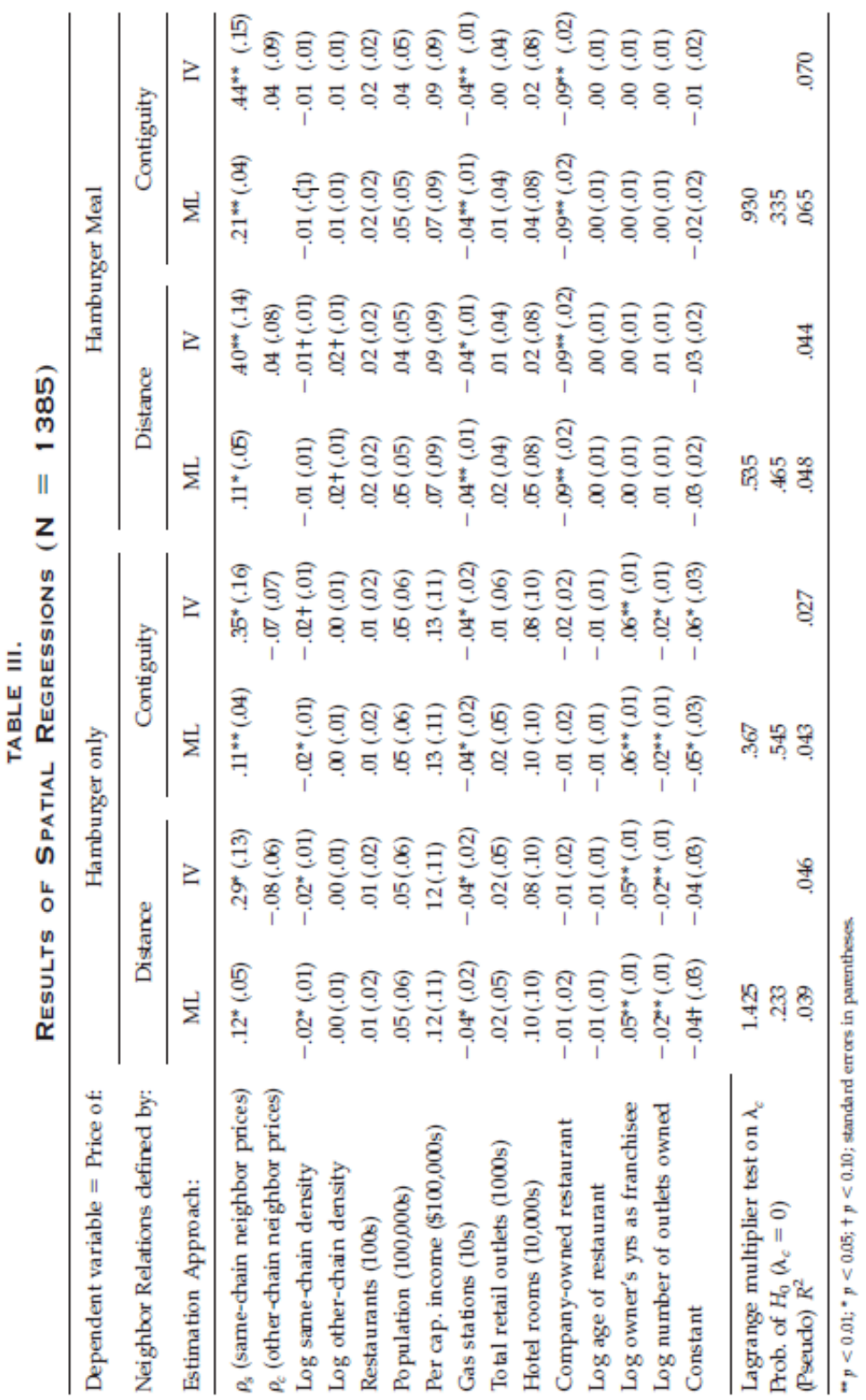


with the matrix $W_{s}$ in every regression is statistically significant, regardless of the neighbor definition (distance radius or market boundary) or the estimation technique used. As the matrix $W_{s}$ is rowstandardized, the value of $p$ of a row-standardized matrix is readily interpretable; the value of $p_{s}$ of 0.12 in the first column of Table III, for example, indicates that increases in prices of a hamburger at neighboring outlets that average 1 cent will lead to an increase in price in the focal restaurant of 0.12 cents. If $W_{s}$ were not row-standardized, the coefficient $p$ would capture not only the average effect of the neighboring restaurant prices but also a possible effect of density of restaurants around restaurant $\mathrm{i}$. From this set of results, I conclude that consumers view nearby locations of the same chain as substitutes.

From the Lagrange-multiplier tests at the bottom of the tables for the ML columns, and the coefficients of $p_{c}$ for the IV columns, the effects of the prices at neighboring outlets of other chains are small and statistically insignificant in all cases. Based on these results, I conclude that there is no significant price competition between the chains, nor is there significant regional cost variation, such as might be based on labor or real-estate costs, that reflects itself in prices.

Turning to other explanatory variables, the same-chain density, as measured by the number of outlets of other owners within the four-mile radius, is statistically significant and negative for the a la carte hamburgers, and negative but insignificant for the value meals. This suggests the further possibility of competition in a way that cannot be captured by the weights matrices of prices (because the weights are row-standardized for each observation). I speculate that the density effect on intrachain price competition may be stronger for the a la carte hamburgers because those prices are usually the ones advertised outside the restaurant. From casual observation, the restaurants are much more likely to hang a banner or paint a window with the announcement "Whopper 99 cents" than they are with the meal prices. Thus, consumers are more likely to be informed about a la carte prices before entering a restaurant.

Among control variables that were included to capture variations in costs and demand, only the gas-station count is statistically significant for both prices across all techniques. The gas- 
station variable was included to capture areas of high demand due to high traffic, which would imply higher prices. Such areas would also be likely to attract many nonrepeat customers, a group for which lower prices would not be effective (as the customers would not know the prices until entering the store). The owners would be likely to charge higher prices in these types of markets. Yet, these gas-station-rich markets have lower prices. I speculate that the low prices may be the result of many substitute products in these markets (convenience stores and mini-markets attached to the gas stations) that are not captured by the density counts or the number of overall restaurants.

Company-owned restaurants charge lower prices for the value meals but not for the a la carte hamburgers, so these results are at least partially consistent with the findings of Lafontaine (1999). Other owner characteristics are important for the a la carte hamburgers but not for the value meals. The number of years a franchisee has operated outlets and the number of outlets owned are both associated with lower prices. Although these two variables are highly correlated (0.6), each retains its significance even when the other is removed from the regressions, indicating that this result is substantive and not a product of multicollinearity. Owners with more experience may be less likely to yield to franchisor suggestions regarding lowering of prices, and these suggestions may be particularly relevant to the a la carte hamburgers. The number of outlets owned may create an externality from lowering prices: customers will be more likely to visit other outlets of the same chain as a result of lower prices, and those outlets may well be owned by the same large owners.

\subsection{Robustness TESTS}

I now briefly present several robustness tests. I examined the robustness of the above results using models with different variables and definitions of variables. I also estimated results on several subsets of data that included only observations of specific chains, observations with high-quality geocodes, observations with other observations very close by, and observations that were owned by franchisees. Finally, I estimated some regressions with owner intercepts. 
First, regressions were estimated with many additional independent variables and different variable definitions. Other zipcode-level census variables included in some regressions but not presented were age and level of education. These were not significant in any regressions estimated. Further, I redefined restaurant density measures using radii of two, three, five, and six miles. Radii greater than four miles did not produce any statistical significance, while radii of two and three miles produced results almost identical to those with the four-mile radius for the value meals. Radii under four miles did not produce significant density results for the a la carte hamburgers. The density variables presented above were logged, but regressions were also estimated with linear versions. The results did not change.

Further, it is possible that no cross-chain competitive effects were found because only a subset of these chains may be viewed as substitutes. Discussions with native Texans indicate that Whataburger may be considered distinct from the other three chains. To investigate this possibility, I recalculated all density measures and weights matrices and estimated all regressions with subsets of the original dataset (1) using Burger King, McDonald's, and Wendy's only; (2) using Burger King and McDonald's only; (3) using McDonald's and Wendy's only; and (4) using McDonald's and Whataburger only. In none of these subsets was there any evidence of cross-chain spatial price correlation. The intrachain price correlations remained for the two subsets that included Burger King. For these subsets, the significance level of the parameter $p_{s}$ for IV for the a la carte hamburgers was lower, but within the $p<0.10$ range. The $M L$ results for the hamburger, and results from all estimation techniques for the value meals, remained at the same significance levels as those presented in Table III. When Burger King was removed from the analysis, the intrachain price correlation ceased to be statistically significant for the hamburger, but the correlation for the value meals remained at the significance levels of the full sample.

Another reason for a lack of significance of cross-chain competitive effects may have been the somewhat inaccurate quality of some of the geocoding. As stated above, the locations of 101 restaurants were estimated using only a 5-digit zip-code centroid. Inclusion of these outlets may have added noise to the weight 
matrices and the density measures. I recalculated all density measures and weight matrices and recalculated all regressions with a subset of the original dataset omitting these 101 outlets. Once again the results remained the same for both intrachain and cross-chain price competition.

Yet another reason for the lack of cross-chain competition may be that the outlets of the chains are typically just too far apartlack of competition may have nothing to do with whether customers view the products as substitutes. I present two reasons why this scenario is unlikely. First, $90 \%$ of outlets have the outlet of another chain within two miles, while $47 \%$ have an outlet of the same chain within that distance. Yet, there is a correlation of prices for the latter case and not the former. If physical distance alone were driving the lack of crosschain competition, we should see far less of an effect on same-chain outlets than we do. Second, 428 outlets have a neighbor from another chain within one-tenth of a mile. I repeated the IV regressions on this subset, and there was still absolutely no evidence of cross-chain price competition. Intrachain competition was statistically significant and higher in magnitude for this sample than for the population.

I also estimated the IV regressions without any companyowned outlets and found that the results are very similar. Without the company-owned outlets, the significance levels of the parameter $p_{s}$ for IV for the a la carte hamburgers were lower, but they were never outside the $p<0.10$ range. The significance level of the parameter $p_{s}$ for the value meals remains consistently significant within the $p<0.05$ level.

Finally, I also estimated regressions with separate owner intercepts. These showed that approximately half of all hamburger price variation is explained by ownership of outlets alone. Future work could examine in more depth the cross-owner variation in price. As more researchers acknowledge frictions, costs, and other idiosyncrasies of pricing, an owner-level study of determinants of pricing would help to provide a better understanding of the pricing process. 


\section{CONCLUSION: IMPLICATIONS FOR STRATEgY AND POLICY}

In the late 1990s, fast-food chains alternated between promotions emphasizing low prices and those emphasizing the quality and uniqueness of their products. The price promotions have been widely acknowledged as ineffective in raising market share at the expense of the other hamburger chains, although they continue to play a prominent, if reduced, role in the strategy of all the major fastfood chains. The application of spatial econometric techniques to hamburger prices in this paper has shown that prices across chains show very little spatial dependence. In other words, this paper finds no empirical evidence of a relationship between a price at one outlet and those of nearby restaurants of the other chains. This finding provides an explanation for why the price promotions have not been effective: if individual franchisees with incentives to maximize profit at their restaurants do not find it optimal to react to the everyday prices of nearby restaurants, then it must be that the products are not close substitutes for the majority of consumers. Thus, while price promotions may have increased sales to those customers who already prefer the products of each chain, it is unlikely that they attracted customers from the other chains. Further, the fact that intrachain spatial correlation of everyday prices does exist indicates that each chain's locations are substitutes for at least some consumers. Therefore, restaurants participating in promotions may be merely enticing customers to substitute away from neighboring outlets of the same chain that are not participating in the promotions.

Of course, my findings do not indicate that the chains' managers can ignore each other when making strategic decisions. The lack of cross-chain price correlation occurs within a certain range of prices and does not indicate that customers would not substitute between these products given greater price differences or that these chains do not compete along dimensions other than price. For example, the loyalty of consumers to the different chains is largely the result of well-thought- out marketing campaigns. Chains create campaigns and new menu items specifically in order to differentiate their products from those of the competition, a particularly valuable strategy in this setting where an oligopoly offering completely 
undifferentiated products would be reduced to profitless Bertrand competition. Burger King's "Have it your way!" campaign was intended as a "direct strike" against McDonald's (McLamore, 1998, p. 187 ) and was very successful. Wendy's "Where's the beef?" campaign similarly raised market share for that chain. These marketing campaigns have attracted the "heavy users," who may be the chains' most valuable customers, because they are often not price-sensitive (Ordonez, 2000).

The evidence that spatial correlation of prices exists within chains indicates that franchisors are locating different franchisees' outlets close enough together that the franchisees may become active competitors or colluders. Whether franchisees should be protected from intrachain competition is outside the scope of this paper. Yet, the evidence of intrachain price correlation presented here implies that by continuing to add new outlets in areas where that correlation is substantial, franchisors will be more likely to antagonize franchisees and increase the probability that they will face laws that would restrict their ability to grow in the future.

\section{Appendix. Detailed SuRvey Description}

An initial survey was conducted on the weekend of February 13-14, 1999. University of Southern California seniors called 1372 restaurants of the four chains and inquired about several prices. These included a single large hamburger (the Big Mac, the Whopper, the Single, and the Whataburger), the single hamburger meal, the "double" version of this burger (only the Big Mac, already a double burger, did not have such a version), and the "double" meal. The students asked whether the meals included a medium or small "fries" and a medium drink. They found that the value meal composition was entirely consistent at all outlets within each chain.

During this first survey, we discovered several issues that had caused problems and rendered some price data unusable. As a result, we conducted a second survey between May 18 and May 22, 1999. Unfortunately, McDonald's was contacted last. Unknown to us at the time, May 21,1999 was the starting date of a nationwide "teenie 
beanie baby" tie-in promotion. The callers had difficulty getting through to many McDonald's as a result, first because of constant busy signals, and later because many restaurants had hooked up answering machines that announced the available toys. Almost all restaurants resumed answering their phones by mid-June, so the McDonald's calls were placed between June 20 and June 25, 1999. While this lag is unfortunate, it is unlikely that many restaurants altered prices significantly in a month.

The problems encountered during the first survey and corrected included the following. First, employees became annoyed when being asked prices for more than two items. The students felt that some prices quoted for subsequent items were merely guesses. Also, some employees, possibly managers or owners, became suspicious and refused to answer any more questions about prices, fearing that the callers were competitors. Thus, the May survey was reduced to only two items: the a la carte flagship hamburger and its associated value meal.

Second - primarily a problem at McDonald's restaurantssome employees would cite the price with tax, while others would cite the price without. Third, a problem that involved all chains other than McDonald's was that some employees would quote a price that included cheese on the hamburger, while others would quote a price without. The McDonald's Big Mac includes cheese in the basic price, and so this was not a concern in that case. A final problem, mostly at Whataburger restaurants, was that employees would often round the price up. For example, they would often quote a Whataburger meal price of $\$ 4$. When questioned about the actual price, the surveyors found that it could range anywhere from $\$ 3.95$ to $\$ 3.99$.

To avoid these problems in the survey in May, the students asked for prices with and without tax, as well as with and without cheese. We also made sure that the employees were not rounding any prices up or down. While this did try the patience of some restaurant employees, at least it convinced me that we were always getting the right prices. Often the employees could not calculate the tax correctly, but at least we were then sure that the lower price they quoted of the two was in fact the correct nontax price used in all regressions. 


\section{REFERENCES}

Anselin, L., 1988, Spatial Econometrics: Methods and Models, Dordrecht, Netherlands: Kluwer Academic.

---- , 1995, SpaceStat Version 1.8 User's Guide, Morgantown, WV:

Regional Research

Institute, West Virginia University.

---- , A. Varga, and Z. Acs, 1997, "Local Geographic Spillovers between University

Research and High Technology Innovations," Journal of Urban Economics, 42,422-448.

Bell, K. and N. Bockstael, 2000, "Applying the Generalized Method of Moments Approach to Spatial Problems Involving Micro-Level Data," Review of Economics and Statistics, 82, 72-82.

Besanko, D., D. Dranove, and M. Shanley, 1996, The Economics of Strategy, New York: John Wiley \& Sons.

Blair, R. and F. Lafontaine, 2002, "Legislating Exclusive Territories: Franchising Encroachment and Legislative Proposals," Mimeo, University of Michigan.

Boots, B., 1980, "Weighing Thiessen Polygons," Economic Geography, $56,248-259$.

Brandsma, A. and R. Ketellapper, 1979, "A Biparametric Approach to Spatial Autocorrelation," Environment and Planning A, 11, 51-88.

Case, A., 1991, "Spatial Patterns in Household Demand," Econometrica, 59, 953-965.

Doane, M. and D. Spulber, 1994, "Open Access and the Evolution of the U.S. Spot Market for Natural Gas," Journal of Law and Economics, 37, 477-517.

Gasmi, F., J. Laffont, and Q. Vuong, 1992, "Econometric Analysis of Collusive Behavior in a Soft-Drink Market," Journal of Economics and Management Strategy, 1, 277-311.

Hepple, L., 1976, "A Maximum Likelihood Model for Econometric 
Estimation with Spatial Series," in I. Masser, ed., Theory and Practice in Regional Science, London Papers in Regional Science 6, London: Pion, 90-104.

Kalnins, A. and F. Lafontaine, 2002, "Multi-Unit Ownership in Franchising: Evidence from the Texan Fast-Food Industry," Mimeo, University of Michigan.

Kaufmann, P. and F. Lafontaine, 1994, "Costs of Control: The Source of Economic Rents for McDonald's Franchisees," Journal of Law and Economics, 37, 417-453.

Kelejian, H. and I. Prucha, 1998, "A Generalized Spatial Two-Stage Least Squares Procedure for Estimating a Spatial Autoregressive Model with Autoregressive Disturbances," Journal of Real Estate Finance and Economics, 17, $99-121$.

Lafontaine, F., 1998, "Retail Pricing, Organizational Form, and the New Rule of Reason Approach to Maximum Resale Prices," Mimeo, University of Michigan.

---- , 1999, "Franchising or Corporate Ownership: The Effect on Price Dispersion," The Journal of Business Venturing, 14, 17-34.

Levy, D., M. Bergen, S. Dutta, and R. Venable, 1997, "The Magnitude of Menu Costs: Direct Evidence from Large U.S. Supermarket Chains," The Quarterly Journal of Economics, 112, 781-825.

---- and J. Reitzes, 1992, "Anticompetitive Effects of Mergers in Markets with Localized

Competition," Journal of Law, Economics and Organization, 8, 427440.

McDowell, B. and C. Ross, 1997, "McD's to Feed Value-Price Move with $\$ 66$ Mil in Ads," Advertising Age, March 3.

McLamore, J., 1998, The Burger King: Jim McLamore and the Building of an Empire, New York: McGraw-Hill.

Ord, J., 1975, "Estimation Methods for Models of Spatial Interaction," Journal of the American Statistical Association, 70, 120-126. 
Ordonez, J., 2000, "Cash Cows: Hamburger Joints Call Them Heavy Users-But Not to Their Faces," Wall Street Journal, January 12, p. A1.

Paul, R., D. Miljokovic, and V. Ipe, 2001, "Market Integration in U.S. Gasoline Markets," Applied Economics, 33, 1335-1340.

Pinkse, J. and M. Slade, 1998, "Contracting in Space: An Application of Spatial Statistics to Discrete-Choice Models," Journal of Econometrics, 85, 125-154.

- - , - , and C. Brett, 2002, "Spatial Price Competition: A Semiparametric Approach," Econometrica, 70, 1111-1153.

Pledger, M., 1997, "McDonald's Hopes 55-Cent Plan Will Cook Up Profits," The Plain Dealer, Cleveland, $\mathrm{OH}$, March 1, p. $1 \mathrm{C}$.

Salvaneschi, L., 1996, Location, Location, Location: How to Select the Best Site for Your Business, Psi Successful Business Library, Portland, OR: Oasis Press.

Slade, M., 1986, "Exogeneity Tests of Market Boundaries Applied to Petroleum Markets," Journal of Industrial Economics, 34, 291-303.

Stigler, G. and R. Sherwin, 1985, "The Extent of the Market," Journal of Law and Economics, 28, 555-595.

Thomadsen, R., 2002, "Price Competition in Industries with Geographic Dispersion: Measuring the Effect of Location on Price in the Fast Food Industry," Mimeo, Columbia University.

Tolnay, S., 1995, "The Spatial Diffusion of Fertility-A Cross-Sectional Analysis of Counties in the American South, 1940," American Sociological Review, 60, 299 -308. 